\title{
La batalla de los escraches de la PAH llevada a la pantalla: YouTube vs. RTVE
}

Ezequiel Ramon Pinat | ezequiel.ramon@uab.cat

Universidad Autonoma de Barcelona

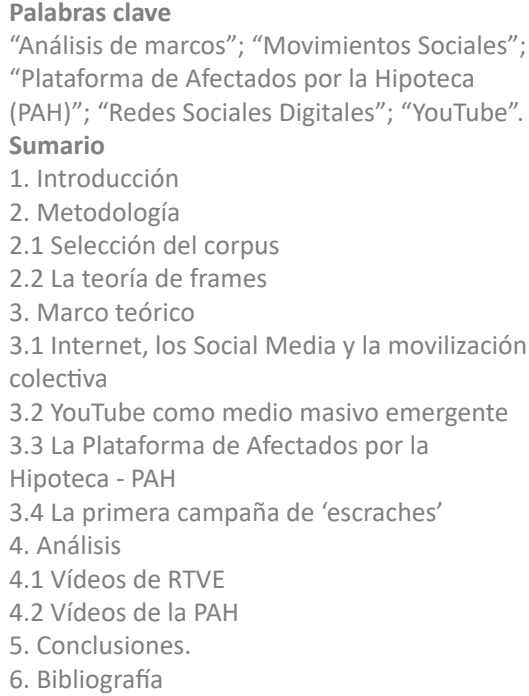

\section{Resumen}

Los movimientos sociales han aprovechado la irrupción de las redes sociales digitales y la proliferación de los dispositivos móviles para difundir sus mensajes y coordinar sus acciones de manera más exitosa. Esta investigación ahonda en el discurso de la Plataforma de Afectados por la Hipoteca (PAH) comparándolo con el emitido por RTVE en la primera campaña de escraches llevada a cabo por la organización. Esto supuso el empleo de un nuevo método de protesta ajeno al repertorio habitual empleado por los movimientos. Esta innovación implicó una batalla por establecer nuevos marcos conceptuales que les dieran sentido. Se visualiza cómo los partidos políticos impusieron sus visiones relacionadas con la violencia desde los medios. En contraposición

las redes, en este caso You'Tube, permitieron a la plataforma emitir un discurso alternativo de interpelación dentro de los cánones democráticos de rendiciones de cuentas con un tono pacifista imperante. Para el análisis se empleó la teoría de marcos.

\section{Cómo citar este texto:}

Ezequiel Ramon Pinat (2019): La batalla de los escraches de la PAH llevada a la pantalla: YouTube vs. RTVE, en Miguel Hernández Communication Journal, n¹0 (1), pp. 19 a 37. Universidad Miguel Hernández, UMH (Elche-Alicante). DOI: http://dx.doi.org/10.21134/mhcj.v10i0.274 


\title{
The PAH escraches battle goes to the screen: YouTube vs. RTVE
}

Ezequiel Ramon Pinat | ezequiel.ramon@uab.cat

Universidad Autonoma de Barcelona

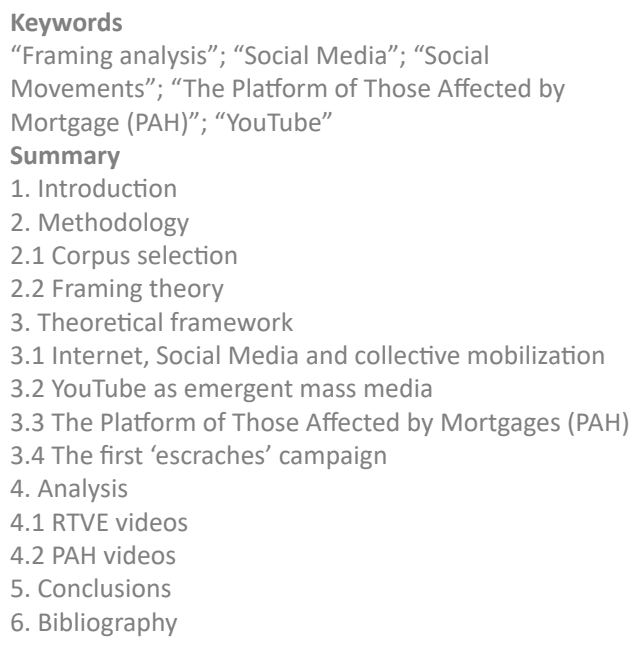

\begin{abstract}
Social movements have taken advantage of social networking services irruption and mobile devices proliferation to spread their messages and coordinate their actions successfully. This investigation delves into the Platform of Those Affected by Mortgage (PAH) discourse, comparing it with the issued by RTVE (the Spanish public broadcasting service) in the first escraches campaign carried out by the organization. This alternative implied the use of a new method of protest outside the usual repertoire employed by the movements. This innovation provoke a battle to establish new conceptual
\end{abstract} frameworks for establishing new meanings. It is visualized how the political parties imposed their visions related to violence from the media. In contrast, the social media, in this case YouTube, allowed the platform to issue an alternative speech of interpellation inside the boundaries delimited by the democratic canons of accountability, with a prevailing pacifist tone. Framing theory was applied in the analysis.

\section{How to cite this text:}

Ezequiel Ramon Pinat (2019): The PAH escraches battle goes to the screen: YouTube vs. RTVE , in Miguel Hernández Communication Journal, n¹0 (1), pp. 19 a 37. Universidad Miguel Hernández, UMH (ElcheAlicante). DOI: http://dx.doi.org/10.21134/mhcj.v10i0.274 


\section{Introducción}

En las últimas décadas hemos podido observar la proliferación de agrupaciones de ciudadanos que con el fin de defender sus intereses e intentar cambiar valores arraigados se valían de las Nuevas Tecnologías de la Información (TICs) para ejercer presión en las instituciones que ostentan el poder e influir en la toma de decisiones. Es decir, actuando al mismo tiempo con un fin pragmático, a corto plazo, en las normas que se adoptan y de manera abstracta, a largo plazo, en la concienciación de la sociedad.

Estas nuevas organizaciones, por una parte, han desplazado a los partidos de masas tradicionales como canalizadores de las demandas y se han convertido en nuevas formas de constitución de la voluntad política (Offe, 1996). Ante la deslegitimación de los partidos la ciudadanía acude a los movimientos de protesta para, por un lado, demostrar su malestar por esta situación y, por otro, influenciar a las élites e instituciones, tal como pudo evidenciarse en los casos de los Indignados y el $15 \mathrm{M}$, el movimiento Occupy en Nueva York y las diversas primaveras árabes. En todos estos tres casos la materialización de la protesta fue posible gracias al auge de las redes sociales digitales y de los dispositivos móviles.

No obstante, el caso de la Plataforma de Afectados por la Hipoteca (PAH) y su lucha por garantizar el acceso a la vivienda pone en jaque el postulado de que tras la posguerra mundial las demandas de las organizaciones estaban relacionadas con cuestiones de identidad y valores intangibles en contraposición a reclamos por necesidades básicas insatisfechas. Entre los tratados que recogen a la vivienda como un derecho fundamental destacan la Declaración Universal de Derechos Humanos de Naciones Unidas, que señala en su artículo 25 que toda persona tiene derecho a una vivienda adecuada (Naciones Unidas, 1948) y la propia constitución española de 1978, que sostiene en su artículo 47:

Todos los españoles tienen derecho a disfrutar de una vivienda digna y adecuada. Los poderes públicos promoverán las condiciones necesarias y establecerán las normas pertinentes para hacer efectivo este derecho, regulando la utilización del suelo de acuerdo con el interés general para impedir la especulación (Agencia Estatal Boletín Oficial del Estado, 2015: 18).

Por lo tanto, la dificultad del acceso a un hogar y su expulsión marca un regreso, o más bien una continuidad, con reivindicaciones de derechos básicos de la ciudadanía que se creían ya consolidados. La Iniciativa Legislativa Popular (ILP) registrada por la PAH pretendía garantizar el acceso a una vivienda digna. Sin embargo, la introducción de un nuevo método de protesta, los escraches, significó un desafío a los límites establecidos. ¿¿En qué medida puede un movimiento social difundir marcos interpretativos alternativos a los de la prensa tradicional? ¿Hasta qué punto reproducen discursos de los medios masivos o, por el contrario, tejen uno propio?

De lo expuesto anteriormente, pueden desprenderse las siguientes hipótesis:

-Al tratarse de un acto de protesta innovador trajo aparejada una lucha por enmarcados muy diferentes, tratando de traer a colación casos anteriores como referencia.

-Ambas partes se presentaban como víctimas y atribuían el peso de la acción al oponente.

-El debate sobre el contenido de la ILP quedó relegado a un segundo plano ante el protagonismo de la novedad de los escraches. 
-La iniciativa del peso del discurso recayó en la PAH y los diputados del PP reaccionaban a rebufo.

-A medida que se acercaba la fecha de la tramitación el tono virulento y beligerante fue in crescendo por parte de los dos actores.

\section{Metodología}

\subsection{Selección del Corpus}

El objetivo de la presente obra es visualizar la divergencia de discurso entre la PAH, en tanto que movimiento social, y los medios masivos, más precisamente en soporte audiovisual. El período escogido es el de la primera campaña de escraches llevada a cabo por la organización, entre el 16 de febrero de 2013 y el 31 de mayo del mismo año, es decir, por espacio de tres meses y medio. Este tipo de protesta no se encontraba entre el repertorio habitual de los movimientos sociales españoles, y dio lugar a una contienda por imponer marcos que la relacionaban desde terrorismo, amenaza, hasta con interpelación democrática y rendición de cuentas.

Por parte de los medios se tomó como referencia material de la Corporación de Radio y Televisión Española, S.A. (RTVE). En el sitio web http://www.rtve.es se buscó el término 'PAH' con la opción de que el criterio de búsqueda esté presente en cualquier parte de la página en el mismo periodo mencionado con anterioridad. Se puso la opción 'Todo RTVE.es' con el fin de incluir los resultados de 'a la carta' y 'televisión'. También se optó por incluir los resultados omitidos por ser similares para posteriormente eliminarlos manualmente. No obstante, se filtró por 'vídeos' descartando noticias de agencias o cortes de programas radiofónicos. Esta primera búsqueda produjo 42 resultados. Tras su visualización se seleccionaron 23 en los que se referían de forma explícita o implícita a los escraches. También se eliminaron las piezas similares, quedando un total de 13

Por parte de la PAH se tomaron los vídeos emitidos en su canal de You'Tube afectadosxlahipoteca, contabilizando un total de treinta en el periodo seleccionado. De ellos, fueron escogidos catorce relacionados con los escraches. Entre los descartados pueden encontrarse parodias de anuncios de bancos, vídeos de manifestaciones, actividades de la plataforma y convocatorias a acciones. Entre los seleccionados están 'De Afectado a Diputado’ en castellano y en otras cuatro versiones subtituladas; nueve de escraches a pie de calle; la voz de un experto, Arcadi Oliveres; 'Mensaje a los votantes del PP'; De Ciudadano a Presidente y 'From Citizen to President' y un simulacro de escrache a Mariano Rajoy.

\subsection{La teoría de frames}

El análisis de marcos (frames) ha venido imponiéndose con fuerza entre los investigadores de las ciencias sociales en las últimas décadas. No obstante, su aplicación carece de una metodología propia comúnmente aceptada, siendo posible encontrar desde análisis cuantitativos, que cuantifican palabras clave que manifiestan un determinado marco, hasta estudios cualitativos, empleando técnicas de análisis discursivo y sociolingüístico (Carratalá Simón, 2012). Los medios, por su parte, tienen un doble efecto estimulando y desalentando frames, dependiendo de que asunto se trate, aunque algunas veces trascienden y operan un modo más general (Gamson, 1992). 
Los marcos pueden definirse como orientaciones mentales que organizan la percepción y la interpretación, focalizando más allá de lo que textualmente puede injerir un discurso de un emisor y acercándose más a la recepción de un mensaje por parte de una audiencia. Para entender un acto comunicativo se precisa la referencia a un metamensaje sobre lo que está sucediendo, es decir, un marco de interpretación que se aplique a ese acto, con un carácter dinámico, colectivo y relevante en las relaciones sociales. La interacción de significado nunca está totalmente determinada, sino que es más bien una producción colectiva. El proceso interactivo consiste no sólo en dos enunciaciones producidas por el hablante y el oyente, sino también en las interpretaciones respectivas de las enunciaciones (Rivas, 1988).

Según Gamson, entre los frames que incitan a la acción colectiva pueden distinguirse tres componentes: injusticia, voluntad e identidad (1992). La ‘injusticia’ va más allá de una percepción de los activistas sobre lo que está bien o mal referido a valores morales. Conlleva una carga emotiva y requiere indignación moral expresada en forma de consciencia política. "Para sostener la acción colectiva los objetivos identificados por los frames deben unir satisfactoriamente lo abstracto y lo concreto" (Gamson, 1992: 33), conectando valores socioculturales amplios con agentes humanos que son susceptibles de acción colectiva. Conectando también objetivos concretos uno puede asegurarse que el impulso no se pierde de manera en que la fuente de injusticia queda intacta.

“El componente de 'voluntad' (agency en el original) hace referencia a la toma de conciencia de que es posible alterar condiciones o políticas a través de la acción colectiva” (Gamson, 1992: 34). En esta categoría puede incluirse también a la legitimación de la acción promovida (Carratalá Simón, 2012). Se sugiere no solo que algo puede hacerse sino que 'nosotros' podemos hacerlo. Ponen énfasis en la eficacia del trabajo en equipo y niegan la posibilidad de que ocurra algún hecho indeseado. Empodera a los ciudadanos definiéndolos como potenciales agentes de sus propias historias (Gamson, 1992).

Finalmente, el componente de 'identidad' apela al proceso de definición de un 'nosotros' en contraposición a un 'ellos' que tendrían diferentes intereses y valores. Sin este agregado de antagonismo la efectividad de una movilización quedaría en una simple abstracción, como por ejemplo hambre, enfermedad, pobreza o guerra. La acción colectiva requiere la toma de conciencia de que existen agentes humanos cuyas políticas o prácticas deben ser cambiadas y de un 'nosotros' que influirá en provocar ese cambio (Gamson, 1992). No cabe perder de vista que, además de delimitar con cierta precisión las partes enfrentadas en el conflicto, "esta representación, a menudo polarizada y maniquea, persigue la fácil y rápida identificación de los individuos que se desea sumar a la acción colectiva con aquella parte que goza de una imagen más amable y positiva" (Carratalá Simón, 2012: 557).

\section{Marco teórico}

\subsection{Internet, los Social Media y la movilización colectiva}

Entre las primeras organizaciones que sacaron provecho de Internet podemos encontrar al Ejército Zapatista de Liberación Nacional (EZLN) de Chiapas, México. Gracias a su uso fueron capaces de establecer una amplia red de apoyo de alcance transnacional que les ofició de escudo protector ante una eventual represión armada por parte del gobierno mexicano (Rucht, 2004). No obstante, más allá del efecto pragmático, tuvo una inesperada repercusión 
que inició un debate sobre el estado de la lucha de clases y sobre la elaboración de alternativas más efectivas a la globalización (Cleaver, 1998).

Russell, por otra parte, realiza una lectura crítica del EZLN y destaca aspectos pocos idílicos del movimiento, aunque también destaca la velocidad con la que sus simpatizantes reaccionaban en Internet al intervenir en foros, siguiendo una estrategia de comunicación alejada de la batalla selvática (2005). Un resultado maniqueo con la mistificación del subcomandante Marcos como 'héroe', de sus seguidores como 'nobles' y el etiquetado de los enemigos como 'bestias neoliberales'.

El movimiento por una globalización alternativa de mediados de los noventa, impulsado por los actos de Seattle y Praga, logró erigirse como actor válido en la esfera política internacional con uso de Internet. Su base, en realidad, estaba formada por una heterogeneidad de ONGs que, aprovechando e impulsando la existencia de la red alcanzaba una dimensión global (Montero, 2001). Su posicionamiento con aquella nueva tecnología les permitió posicionarse como nuevos protagonistas en el ámbito mundial con una imagen innovadora, moderna, horizontal, ágil y joven, aunque también estuvo marcado por la violencia de sus acciones.

Desde la perspectiva de la comunicación, la plataforma de contrainformación Indymedia fue un ejemplo paradigmático de la creación de un medio alternativo ante el fracaso con la relación con la prensa tal como lo exponía Ruch (2004). Apoyada en formatos existente en publicaciones impresas, supuso una voz online para los movimientos sociales que deseaban un espacio de expresión al margen de los medios hegemónicos. Indymedia innovaba siendo una web no moderada con epicentro en Estados Unidos y Europa. Constituyó un precedente de publicación abierta y de comentarios en foros cuando en la red esas prácticas todavía no eran habituales. A pesar de que todavía está activa, con la llegada de las redes sociales la contrainformación ha perdido relevancia como función comunicativa activista (Vila Alabao, 2014).

Pérez Rioja califica a Indymedia como un medio pionero en permitir la publicación abierta de noticias bajo el lema "no odies a los medios, conviértete en uno". "Internet dejaba de ser un campo restringido a personas con conocimiento tecnológico avanzado para abrirse a todo el mundo y posibilitar la democratización mediática" (2014: 67). Señala, además, un paralelismo con los grupos de fotógrafos obreros de Alemania que en los 30 llegaron a tener su propia revista. En la actualidad, destaca a la plataforma Bambuser como heredera de aquel espíritu conformado por ciudadanos anónimos que sienten la necesidad de enseñar el mundo desde otro punto de vista, "siguiendo el mismo concepto adaptado a las nuevas circunstancias político-sociales y a las nuevos parámetros organizacionales de la sociedad-red” (Pérez Rioja, 2014: 68).

Kahn y Kellner señalan el rol fundamental que jugó Internet en el movimiento en contra de la guerra de Irak en 2002 y 2003, desafiando a la política beligerante de la administración Bush tras el 11S (2004). Desde los sitios Moveon.org, Internationalanswer.org y Unitedforpeace.org, entre otros, usaban la red para poner en circulación información en contra de la guerra, organizar manifestaciones y promover una diversidad de actividades, teniendo como punto álgido los actos en varios lugares del globo el 15 de febrero de 2003.

Ambos autores también agregan las profundas transformaciones que experimentó Internet en todo este tiempo. Cambios relacionados con el diseño de los sitios, de los blogs y la aparición de comunidades virtuales, la evolución de la arquitectura del hipertexto, la aparición de fenómenos como la cultura hacker ${ }^{1}$. y el ciberterrorismo. Espacios tecnológicos que antes permanecían

\footnotetext{
${ }^{1}$ Para ahondar en los fundamentos de la cultura hacker consultar Himanen, P.ekka (2004): La ética
} del hacker y el espíritu en la era de la información. Barcelona, Destino. 
apartados han pasado a tener un papel central en la militancia diaria en Internet (Kahn y Kellner, 2004).

\subsection{YouTube como medio masivo emergente}

La plataforma de vídeos YouTube fue fundada en 2005 por Jawed Karim, Steven Chen y Chad Hurley, tres estadounidenses que se conocieron trabajando en PayPal. Dos años más tarde contaban con 69.800 .000 vídeos alojados y 74,5 millones de visualizaciones. Esto convirtió a YouTube en "el mayor medio de comunicación de masas del mundo" (Castells, 2009: 103). No obstante, fue apenas dos años más tarde cuando dio el gran salto al ser comprada por Google por 1.600 millones de dólares. "En 2007, Google, Apple, Yahoo y Microsoft redoblaron sus esfuerzos por competir con conglomerados multimedia más tradicionales para controlar el cada vez más lucrativo negocio de vídeos en línea.” (Castells, 2009: 118).

En 2015 YouTube contaba con más de mil millones de usuarios registrados distribuidos en 75 países. Cada minuto se subían a la web 300 horas de vídeo. La cantidad de horas de visualizaciones de vídeos mensuales aumentaba a razón de un 50 por ciento en relación al mismo periodo del año anterior. El carácter transnacional de la red social quedaba evidenciado en el hecho de que el 60 por ciento de las visualizaciones son de un estado distinto al del creador (YouTube, 2015).

Sin embargo, no existen solamente material elaborado por aficionados. Con el auge de los social media los medios tradicionales se encontraron ante la disyuntiva de volcar sus materiales en las redes para poder ganar visibilidad a costa de perder beneficios monetarios. De esta manera, pequeñas y grandes cadenas de televisión, de la talla de la BBC, Al Jazeera, France 24, Deutsche Welle, CNN, Fox News y TVE, entre otras, también se volcaron en YouTube a fin de no ceder espacio a la competencia. Esto produce que sobre un acontecimiento puedan convivir vídeos realizados con dispositivos móviles por ciudadanos y una mirada profesional y elaborada en la misma plataforma.

El carácter participativo de la red social, en la que colgar un vídeo está al alcance de cualquiera con nociones básicas, choca con las restricciones de derechos de autor y la adecuación del contenido. En estados represivos puede suceder que, además de la censura oficial, los usuarios borren sus mensajes retroactivamente con el fin de evitar represalias. En la revolución egipcia de 2011 quedó evidenciado la fragilidad del contenido online, especialmente en Facebook y Twitter, en donde el diez por ciento del material ya no se encontraba un año más tarde (Hanna, 2013).

\subsection{La Plataforma de Afectados por la Hipoteca (PAH)}

A comienzos de 2009 se constituye en Barcelona, ciudad con fuerte tradición de lucha de movimientos sociales, la Plataforma de Afectados por la Hipoteca (PAH) con el fin de dar cobertura a quienes no estaban en condiciones de hacer frente al pago de sus cuotas hipotecarias. El movimiento era la continuación de 'V de Vivienda', nacido en mayo de 2006 e integrado por adolescentes imposibilitados de emanciparse y optar a una vivienda digna (Alemany y Colau, 2012).

Tres años más tarde, el estallido de la burbuja inmobiliaria y el comienzo de la crisis económica provocó un cambio de escenario, en el que la problemática de la vivienda se convertía en más traumática, disparándose el número de casos de familias que eran enviadas a la calle, sin protección jurídica ni asistencia estatal. Ya no se trataba de que la juventud pudiera acceder a 
una vivienda sino que las familias no las perdieran, arrastrasen otras propiedades junto con problemas de salud y deudas imposibles de afrontar. Esta nueva refocalización dio a luz a la PAH. El movimiento encontraba así una vía de paso ante un conflicto creciente de manera exponencial, lo que Tarrow denomina "formas de acción colectiva que rodean el armazón de la política institucional y crecen o disminuyen con el ritmo de los cambios en las oportunidades y las restricciones políticas” (2004: 106).

La plataforma adopta una estructura horizontal, descentralizado, más allá de que exista una gran diversidad de grados de implicación de los activistas. La dinámica de trabajo que pregona es asamblearia con una periodicidad semanal, en donde cada afectado narra su caso particular buscando despertar adhesión en el resto de asistentes, obligando a una actitud pro-activa. Son informados de los pasos a seguir, de las vías administrativas y jurídicas que se deben agotar antes de llegar al lanzamiento: acudir a Servicios Sociales, a la Oficina de Vivienda y contactar con el abogado de oficio (Sala, 2018).

La organización persigue instalar la concepción de la vivienda como un derecho en el campo abstracto, intangible, y al mismo tiempo trabaja en demandas concretas como la aprobación de una ley con tres exigencias: la detención de los desahucios, la opción de la dación en pago y la posibilidad de un alquiler social asumible que no supere el 30\% de los ingresos de una unidad familiar. Posteriormente se añadieron dos más: la garantía de suministros básicos y el aumento del parque de vivienda pública, conformando las llamadas ‘5 de la PAH’ (Sala, 2018).

\subsection{La primera campaña de 'escraches'}

A finales de 2010, ante la constatación de que la ley hipotecaria española no brindaba cobertura jurídica a quienes caían en situación de impago y ante el vertiginoso aumento de la cantidad de morosos y ejecuciones, la plataforma decide cambiar la ley hipotecaria impulsando una Iniciativa Legislativa Popular (ILP), un engorroso y dilatado proceso que contempla la democracia española para dar trámite a iniciativas de la ciudadanía cuya resolución no es vinculante. En ese momento, el 15M todavía no había estallado y la fuerza de la PAH era poca, ya que solamente había arraigado en Cataluña y Murcia. Sin embargo, una nueva legislación se antojaba un recurso mucho más efectivo que la desobediencia diaria a pie de calle deteniendo los desalojos de uno en uno.

Pese a la poca incidencia efectiva, la iniciativa promovida por la PAH experimentó numerosos obstáculos, que por un lado entorpecieron el proceso, pero por otro provocó mayor expectación y participación. En febrero de 2013 se alcanzaron las 1.402 .854 firmas en los pliegos para presentar en la cámara de diputados, cifra holgadamente superior al medio millón necesario. En el momento de la puesta en marcha de la recogida la infraestructura de la plataforma era exigua y no hubiera sido suficiente para alcanzar dicha cantidad. El éxito, en buena medida, estuvo marcado por la extensión a otros colectivos, sindicatos y movimientos vecinales: el Observatorio DESC, la Confederación de Asociaciones de Vecinos de Catalunya CONFAVC, UGT, CC. OO. y la mesa del Tercer Sector Social de Catalunya, que sí contaban con una red social más amplia.

La modificación de la ley hipotecaria en un primer momento contemplaba solamente la moratoria de los desahucios por razones económicas. Posteriormente, fueron añadidas la posibilidad de la dación en pago retroactiva y la reconversión en forma de alquiler social (a un precio significativamente menor que al del mercado) de las viviendas vacías en manos de las entidades bancarias. La propuesta se llevó a cabo sobre una base jurídica desarrollada previamente por 
el observatorio de derechos sociales DESC, que ya había colaborado con otros movimientos sociales en la elaboración de herramientas e instrumentos jurídicos, con la colaboración de la Comisión de Defensa del Colegio de Abogados de Barcelona y la Comisión de Derechos Humanos del Colegio de Abogados de Girona (Alemany y Colau, 2012).

La iniciativa entró en el registro de la Mesa del Congreso en marzo de 2011. Presidida por José Bono Martínez, el órgano estaba conformado por tres miembros del PSOE, por cuatro del PP, uno de CiU y uno del PNV, es decir, por una amplia mayoría del PP y PSOE. Dos semanas más tarde la mesa rechazó su tramitación alegando que ya había una propuesta similar presentada anteriormente. Este hecho tomó por sorpresa a la plataforma. Más tarde, la publicación Público. es descubrió que detrás de esta propuesta estaba Los Verdes Ecopacifistas, un pequeño partido político con lazos con el sector inmobiliario en la Comunidad Valenciana ${ }^{2}$. El escándalo desatado empujó a este grupo a retirar su propuesta.

Posteriormente, la Mesa postergó su aceptación aludiendo a que nunca se había dado una situación de ese tipo y que no estaba contemplado como debería actuar. Para ese momento llegaron las vacaciones de verano y para septiembre finalmente la nueva propuesta entró a tramite, en vísperas de las elecciones generales de 2011. La mesa finalmente aceptó la tramitación justo antes de disolverse, quedando su tratamiento para la siguiente legislatura.

En víspera de su tratamiento en la Cámara de Diputados, durante las dos primeras semanas de febrero la PAH interpeló a todos los partidos con representación parlamentaria para solicitar por escrito su apoyo a la aprobación de la ILP original presentada por la organización. Consciente de la disciplina de partido y del escaso interés mostrado por modificar la ley hipotecaria, la PAH decide llevar una campaña de escrache a diputados del PP, que por su condición de tener una mayoría parlamentaria sería suficiente para su aprobación.

A pesar de no haber incorporado el término 'escrache', la Real Academia Española sí ha incorporado 'escrachar', en cuya segunda acepción hace mención a "fotografiar a una persona" en castellano rioplatense coloquial (RAE, 2014), aunque una explicación más fidedigna sería dejar en evidencia, más que tomar una imagen. No obstante, el diccionario de americanismos de la Asociación de Academias de la lengua española lo define como "manifestación popular de denuncia contra una persona pública a la que se acusa de haber cometido delitos graves o actos de corrupción y que en general se realiza frente a su domicilio o en algún otro lugar público al que deba concurrir la persona denunciada” (ASALE, 2010).

Los escraches implicaba la instalación de un nuevo tipo de protesta fuera del repertorio habitual empleado por los movimientos sociales en España. Tarrow identifica tres tipos básicos de acción colectiva: la violencia, la alteración del orden y lo convencional (2004). Los tres incorporan, en mayor o menor grado, las propiedades de desafío, incertidumbre y solidaridad. La violencia es la más fácil de iniciar, pero queda limitada a pequeños grupos de radicales dispuestos a causar daños y a arriesgarse a ser reprimidos. La convención podemos ubicarla en el polo opuesto, tiene la ventaja de basarse en rutinas que la gente conoce y las elites aceptan e incluso facilitan. "Ésta es la causa de su predominio numérico en el repertorio pero también de su institucionalización y su falta de entusiasmo" (Tarrow, 2004: 152).

Los escraches pueden ubicarse en la tercera forma enumerada anteriormente, la alteración del orden establecido, que rompe con la rutina, sorprende a los observadores y desorienta a las

\footnotetext{
${ }^{2}$ Reportaje disponible en https://www.publico.es/actualidad/pantalla-verde-bloquea-dacion-pago.html [Última consulta 9 de diciembre de 2018]
} 
élites, al menos durante un tiempo. "La alteración del orden es la fuente de buena parte de las innovaciones del repertorio y del poder del movimiento; pero es inestable y degenera fácilmente en violencia o se esclerotiza en convención" (Tarrow, 2004: 152). "Para mantener las acciones que desafían el orden público se precisa un alto nivel de compromiso, la capacidad de sorprender a las autoridades y resistir las tentaciones tanto de la violencia como del convencionalismo. Por estas tres razones, la alteración del orden es un arma poderosa pero inestable de la acción colectiva." (Tarrow, 2004: 144).

\section{Análisis}

\subsection{Vídeos de RTVE}

Pieza 1.a

(Cristina Cifuentes): "Me resulta muy llamativo que esos grupos, esa lideresa, que está liderando ese grupo supuestamente para defensa de los desahucios, yo creo que en realidad ahí hay intereses de otro tipo bueno, últimamente parece que tienen también ciertas inquietudes de apoyo a grupos filoetarras o proetarras."

Marcos:

-No podemos atacar la lucha contra los desahucios, es visto como algo noble, los sondeos avalan la $\mathrm{PAH}$ en ese sentido, entonces hay que sugerir que hay otros intereses que, al no explicitarlos, se da a entender que son espurios y no transparentes.

-Crear una similitud con ETA, para justificar la lucha y eliminación de la PAH por el bien de la democracia. Por lo tanto, el partido mejor valorado para luchar contra ellos es el PP.

-En realidad, no se trata de un grupo de gente corriente que lucha por su vivienda sino que son llevados por una lideresa hacia otro terreno que no es ese.

Pieza 1.d

(Voz en off): "Pero desde el País Vasco el presidente del PP apunta que las formas de la plataformas se parecen a las de la violencia callejera e incluso, dice, a los nazis."

(Antonio Basagoiti - Presidente del PP vasco): "No se ve ninguna diferencia, ni en los gritos, ni en la actitud, ni en el fondo entre los que venían del mundo de ETA a acosarnos y los que van ahora con la excusa de las hipotecas a acosar a los del partido popular."

(Begoña Barrutia - Plataforma de Afectados por la Hipoteca de Bizkaia): "Nosotros no acosamos, nosotros lo que hacemos realmente es enseñarles que es lo que opina la ciudadanía. No se les increpa, lo hacemos desde una distancia prudencial."

(Elena Valenciano Vicesecretaria General del PSOE): "Ni se puede acosar a los diputados del PP ni se puede criminalizar a los movimientos ciudadanos, ninguna de las dos cosas"

Y en opinión de la dirección del PP el objetivo de cualquier causa se pierde por la violencia Esteban Gonzalez Pons, Vicesecretario de Estudios y Programas del PP: "Porque hoy se hace a favor de los desahucio que es una causa que todo el mundo comprende, pero mañana puede servir a cualquier causa porque el miedo del parlamentario se habrá convertido en un medio habitual, es decir la antidemocracia habrá contaminado a la democracia"."

-Ellos usan la violencia, entonces sus reivindicaciones pierden legitimidad por esta misma razón. 
-Seguro que no están reclamando por los desahucios sino que tienen otros intereses o bien ocultos, o bien tan malvados que no pueden decirse.

-Pendiente resbaladiza: por una causa como los desahucios no está tan mal protestar, pero en una esta forma de protesta irá a más, de forma habitual, por cuestiones que no serán dignas y los parlamentarios tendrán miedo de actuar como corresponda, gobernarán según quieran los violentos.

-Los escraches son acoso y no deben hacerse con los diputados, al decir que tampoco a los del otro partido se está enmarcando como una disyuntiva entre democracia-no democracia.

-Al decir que son acoso no los estoy criminalizando, ellos sí que lo están haciendo.

Pieza 1.e

(Voz en off): Y en medio de todo una agria polémica. Por las protestas de estos días de afectados por la hipoteca siguiendo a diputados del PP, y por las palabras de la delegada del Gobierno en Madrid que vinculó al colectivo con grupos filoetarras.

(Ada Colau - Portavoz de la PAH): "Es muy grave y exigimos la dimisión inmediata de esta delegada del gobierno.”

(Ignacio González - Presidente de la Comunidad de Madrid): "Esto no lo ha dicho la delegada o no lo ha querido decir, y creo que se ha sacado de contexto."

(Mariano Rajoy): "No es democrático ni es justo ni es propio de un país serio el que se acose a personas y se les intimide en sus casas, que se empapelen sus casas con carteles con su cara." (Voz en off): "La plataforma ha recordado que empezó su carrera en solitario hace cuatro años y que siempre ha sido pacífica."

-Es una confusión que se parezcan la PAH y ETA

-Los escraches no atentan contra políticos sino contra sus vidas privadas, fuera de la actividad pública. Es en sus casas, que debería ser un territorio impenetrable amparado por el derecho a la intimidad y de protección a los menores.

-Sí es cierto que la PAH en sus orígenes era una organización pacífica, pero ahora a perdido la paciencia y ha adoptado una vía violenta.

Pieza 1.f

(Voz en off): "Precisamente lo que estos días levanta más polvo es el llamado escrache, es decir, el escarnio de los afectados por la hipoteca a diputados del partido popular."

-Define los escraches como una burla tenaz que se hace con el propósito de afrentar.

-Las víctimas son cargos públicos solo de un determinado partido político, es un asunto con intereses partidistas.

Pieza 1.g

(Voz en off): "Y en tono muy duro ha condenado las protestas en las casas de los políticos."

(Mariano Rajoy - Presidente del Gobierno): "La intimidación es lisa y llanamente algo contrario 
a la democracia, y nadie merece ser acosado, denigrado, amenazado ni intimidado, menos aún si el motivo de esa presión, y de esa amenaza, es haber sido elegido por la mayoría de los ciudadanos, que es lo que le pasa a los diputados del partido popular."

-Es en el domicilio, vivienda, reducto familiar que no debe ser vulnerado.

-No es que los políticos no se lo merezcan, es que ni siquiera nadie debe sufrirlo.

-El motivo no es la ILP ni la ley hipotecaria, es porque fueron votados por una mayoría.

Pieza 1.j

(Alfonso Alonso - Partido Popular): "Hay algunos que están instrumentalizando políticamente ese movimiento social."

(Aitor Esteban PNV): "Lo que creo es que no se puede abusar de la libertad de expresión para coaccionar a los demás."

-El movimiento social tiene una imagen positiva entre los votantes del partido, por lo tanto, no se discute sus intenciones, sino que existe otra gente que saca provecho político de ellos y por lo tanto hay que ir en contra de la organización.

-Un abuso es algo que debe evitarse, por lo tanto, aunque la libertad de expresión sea un derecho, si se da abuso debe recortarse.

Pieza 1.k

(Voz en off): "Los asistentes se sienten amparados por la ley y no temen a la amenaza de ser identificados."

-Doble lectura: La ley está mal hecha, está legitimando actitudes represivas que la transgredan por parte de las fuerzas del orden. Eso se manifiesta en que tienen tan poco miedo y están tan dispuesto a todo que incluso desafían a la policía.

\subsection{Vídeos de la PAH}

Pieza 2.g

(Testimonios de afectados): "Estamos defendiendo nuestros derechos." (...) "No cobro ninguna ayuda de ningún lugar.” (...) "Soy ingeniera industrial y cobrábamos en casa bastante bien.” (...) "Sea consecuente, escuche a la ciudadanía y vote sí se puede."

"Soy Olga, estoy aquí con mis dos hijas, se llaman Adriana de cuatro años y Paula de diez años." (...) "Antes de venir a su casa le hemos mandado invitaciones para que vengan a las asambleas."

-No atacamos, sino que nos defendemos.

-No queremos sacar provecho del estado, reclamamos lo que nos corresponde.

-No soy una trabajadora no cualificada que obtuvo el crédito de manera irresponsable.

-Nosotros somos la ciudadanía. 
-Tenemos nombre y familia.

-Llegamos a este punto luego de intentar dialogar con ustedes.

Pieza 2.a

(Diferentes afectados se dirigen a un votante del PP de manera íntima, en un primer plano al mismo nivel que la cámara): "Nos dirigimos a ti, votante del PP porque necesitamos tu ayuda. No somos el enemigo. No somos violentos. Ni mucho menos terroristas, pero que tontería. Creemos en la justicia y en la democracia. Y en el diálogo. En la paz. Somos los desahuciados. Los desposeídos. Los estafados. Tus conciudadanos. Tus vecinos. Tus familiares. Tus amigos”. "Entre nosotros hay votantes de todos los partidos. Soy militante del PP y afectado por una hipoteca. Y yo confiaba en que habría un buen cambio y ahora a mi hijo lo van a desahuciar. Que no nos dividan. Que no nos asusten. Porque el gobierno no nos escucha. Quizás a ti te escuchen más si les haces llegar este mensaje. La Iniciativa Legislativa Popular nos ha devuelto la esperanza a miles de familia. La esperanza en un futuro. En una segunda oportunidad. Los diputados del partido Popular tienen mayoría absoluta. Por eso los presionamos. Porque la decisión de aprobarla depende de ellos, y solo de ellos. Que no la desvirtúen. Llevamos cuatro años parando desahucios inhumanos. Cuando gobernaba el PSOE y ahora con el PP. Europa nos ha dado la razón, son desahucios ilegales. Hemos agotado todas la vías de diálogo. El gobierno no quiere actuar. Defiende los intereses de los bancos. Y nos criminalizan a nosotros, las víctimas. Mienten, nuestras propuestas no llevarían al caos. Y Salvarían a miles de familias de las ruinas, de la desesperación. ¿No es eso lo más importante? ¿Salvamos a los bancos y dejamos caer a los deudores de buena fe? Una sociedad que sacrifica a los suyos es una sociedad enferma. Que el egoísmo no venza. Que la avaricia de unos pocos. Que las mentiras no nos separen. Nuestra situación es límite, no podemos esperar. Estamos luchando por nuestros derechos. Que son tus derechos. Ayúdanos como te ayudaríamos nosotros si estuviéramos nosotros en tu situación, y como te ayudaremos si llegas a estarlo. Apelamos a principios universales que no son ni de izquierdas ni de derechas. Son de todos. Y son lo más valioso que tenemos. La dignidad, la solidaridad, la justicia y el amor. Defendamos juntos esos principios. Porque sin ellos no somos nada. Pon una tela verde en tu balcón. Ponte algo verde. La primavera no es roja ni es azul, es verde. Y es de todos. Como la esperanza."

-Hablamos directamente con los votantes, no con los políticos, sin intermediarios, recreación de intimidad. No creas lo que te dicen, no importa lo que piensen los candidatos sino los votantes.

-No somos una masa irracional, sino que apelamos a la calma.

-Somos uno de los tuyos, tú podrías estar en nuestro lugar, de hecho hay militantes del partido que están en nuestra organización.

Pieza 2.i

(Una afectada): "La clase política está muy alejada del pueblo"

(Antonio Gallego - Diputado): "Voy a votar lo que me de la gana, a mi está gentuza no me va a intimidar."

(imagen del despacho y asiento vacío del diputado)

-En realidad habla para las cámaras de TV, pero detrás de los focos se niega al diálogo. 
Reclamamos un encuentro pero solo nos dan la espalda.

Piezas 2.j y $2 . \mathrm{k}$

(Una afectada): "Le doy las gracias a Ada Colau y a mucha otra gente que está en la plataforma y que no sale en la tele."

(Una afectada): "No soy criminal, soy pobre."

(Una afectada): "Cuando oigo a los políticos decir "vienen a nuestras casas y es que a los niños los tienen traumatizados', ¿y mis hijos y los de todo el pueblo qué?”

-No es en domicilios particulares, sino en su trabajo, en la sede del PP, desarticulando la inviolabilidad del hogar.

-Detrás de lo que muestra la televisión hay más gente anónima que trabaja honestamente. La PAH es más que una moda mediática.

-El delito no son los escraches sino ser pobres.

-Nuestros hijos tienen los mismos derechos que los suyos, que están sometidos a la violencia de sufrir desahucios.

Pieza 2.1

(Voz en off): "Nos llamasteis terroristas, nazis, y nos acusasteis de amenazas y coacción. Por nuestro lado solo habéis encontrado argumentos. El proyecto de ley que queréis aprobar no contempla ninguna de las medidas de mínimos de la ILP, está hecha a golpe de telefonazos de los jefazos de la banca criminal, esto no es democracia."

-Ellos eran los violentos, negándose a dialogar porque no tienen la razón, nosotros tenemos las razón de nuestro lado, por eso aportamos argumentos.

-A nosotros no nos escuchan pero a los poderosos sí.

Pieza 2.m

(El vídeo está grabado de una proyección en un televisor)

(Diferentes miembros de la plataforma): "Señor presidente del gobierno, le ha parecido a usted profundamente antidemocrático que nos acerquemos a sus señorías con asambleas y pegatinas para demostrarles una realidad que están ignorando."

"Quizás nos escuche más si nos dirigimos a usted de la misma forma en la que nos habla últimamente. A nosotros, ciudadanos y ciudadanas, nos parece profundamente antidemocrático que comparezca a través de una pantalla sin responder a las preguntas de los medios."

"Proteger los intereses de una banca acosadora y llamar acosadoras a sus víctimas. Más del 80 por ciento de la población apoya nuestras propuestas. Las políticas del PP, del PSOE y los desmanes de la banca han arruinado el país. Pagaremos su fiesta durante años con nuestra sanidad, nuestra educación, nuestras pensiones, nuestras viviendas, hipotecando el futuro de todos, de un país entero."

"Queremos justicia, y exigirla es, mire usted, profundamente democrático." 
-Uso de ironía, retransmisión en vídeo recreando una rueda de prensa habitual de Mariano Rajoy a través de un televisor de plasma. Se ubica la misma altura que el interlocutor.

-Nos acercamos a ellos para que conozcan una realidad que no conocen.

-Nosotros no somos antidemocráticos, usted sí actúa de esta forma.

-No se trata de la vivienda solamente, sino que además afecta a todos los derechos básicos y comunes de la ciudadanía.

-La población está de nuestro lado, nosotros somos la mayoría, y si nos apoyan es porque tenemos razón.

\section{Conclusiones}

Al tratarse de un acto de protesta innovador trajo aparejada una lucha por enmarcados muy diferentes, tratando de traer a colación casos anteriores. Desde el Partido Popular lo relacionaron con actos de terrorismo y ataques a la esfera privada y desde la PAH con rendición de cuentas democrática e interpelaciones en la vida pública de los diputados.

Por otra parte, ambos bandos parecen acordar que los desahucios son una tragedia y que es un motivo de movilización. El electorado del PP también lo piensa. Para instalar un frame propio es necesario ir a la arena del oponente y hablar su mismo lenguaje y hacerlo desde allí. Negar los desahucios hubiera provocado más irritación entre los propios miembros del partido y un distanciamiento mayor. Esto marca un éxito para la plataforma, ya que se ha consolidado el drama de los desalojos en el seno de la sociedad y definitivamente se ha instalado en la agenda política.

También se ha evidenciado como ambas partes se presentaban como víctimas y atribuían el peso de la acción al oponente. El primero en encuadrar el accionar del oponente con el terrorismo etarra fue el PP a través de la entonces Delegada del Gobierno en Madrid, Cristina Cifuentes, el 25 de marzo. Por su parte, los activistas se presentaban como las víctimas de la desprotección de la legislación actual, que sufrían el acoso de las entidades bancarias. La mención de los daños ocasionados al resto de la familia, y a los menores de edad principalmente, fue esgrimida por los dos actores.

El debate sobre el contenido de la ILP quedó relegado a un segundo plano ante el protagonismo de la novedad de los escraches. En el contenido emitido por RTVE apenas se hace mención al contenido de la ILP, que efectos tendría y su alcance, en cambio sí que se centra en el debate sobre la legitimidad y validez de los escraches como método de presión.

Otro eje en el que giró la campaña fue el de democracia-antidemocracia. Ambos lados trataron de adjudicarse la legitimación de actuar en nombre de la mayoría y de salvar al sistema político actual, acusando al rival de ponerlo en peligro. La lucha por apropiarse de los mismos valores hace difícil definir los resultados de ganadores vs. perdedores, quedando en manos de quienes reciben el mensaje.

Por otra parte, la iniciativa del peso del discurso NO recayó en la PAH y los diputados del PP NO reaccionaban a rebufo. A pesar de ser actores pasivos en las protestas, el enmarcamiento 
como actos terroristas condicionó la comunicación. La PAH optó por desmentir y afirmar tibiamente que los terroristas eran "los otros". Bien podrían haber optado por no referirse en absoluto a la acusación, evadirla, o prever con anterioridad su utilización para apropiarlo. En esta ocasión su efectividad es dudosa, ya que se apela a un frame cuya relación estuvo cultivada más de una década. En cualquier caso tuvo un efecto negativo para la campaña de escraches.

En otro momento en el que la plataforma va por detrás es en las acusaciones del grado de democracia-antidemocracia y de violencia-pacifismo. En las piezas de RTVE podían oírse la defensa de los diputados del PP esgrimiendo sus derechos a no ser increpados y la violencia de los activistas mientras en los videos de YouTube el movimiento va desmintiendo las acusaciones y enseñando una imagen que las contrarreste, por lo tanto, reaccionando al discurso que anteriormente fue articulado por el PP.

A medida que se acercaba la fecha de la tramitación el tono virulento y beligerante fue in diminuendo por parte de los dos actores. Desde RTVE Ignacio González, del PP, desestimó la vinculación que Cifuentes había formulado con grupos etarras e incluso la relación con el nazismo. Por su parte la PAH, desde el canal afectadosxlahipoteca se veía como con el correr de los días, y ante las críticas por la inviolabilidad del domicilio privado, se pasó a los despachos y administraciones públicas para acabar con un acto en plena calle, en las afueras de la sede del partido político en Barcelona.

Mientras en RTVE se enmarcaba como un enfrentamiento en el que se daba voz a los políticos que hablaban sobre la pertinencia o no de los acosos, en YouTube la plataforma lo hacía como un diálogo que no era posible por la negativa de la otra parte. La legitimidad del método de protesta quedó relegada en aras de las razones de la necesidad, alcance y efecto de la ILP. También daban voz a los casos particulares, poniendo rostro al drama, aspecto ausente en el contenido de RTVE. Por lo tanto, sí que en el presente caso una red social digital ha permitido a un movimiento social tejer un relato alternativo al de los medios tradicionales.

El dedicar los escraches a diputados de un solo partido constituyó un error en la plataforma, ya que permitió a la formación enfocarlo como un ataque partidista. Es cierto que con la mayoría absoluta para la aprobación de la ILP hubiera bastado con sus votos, pero les posibilitó un argumento válido de defensa, incluso como mayoría parlamentaria para valerse como la opción democrática versus la anti-democrática encarnada por la PAH.

En diversas piezas de RTVE se enfocaba en el mismo plano activistas de la PAH y policías antidisturbios fuertemente armados, incluso con cascos en un clima tenso. Más allá de que no se registraran incidentes en los actos de protesta, el enmarcado era evidente de conflicto e intimidación y daba a entender que las fuerzas del orden debían proteger a políticos indefensos e inofensivos.

Este tipo de protesta, que no se encontraba en el repertorio de acciones comúnmente empleadas, implicaba para un movimiento social como la PAH la ventaja de un fuerte impacto generalizado y visibilidad en la prensa. Pero por otra parte, el riesgo de lo impredecible que puede ser en la aceptación de sus simpatizantes y ciudadanos. Al tratarse de demandas sobre el derecho de la vivienda, fuertemente arraigado en el acervo cultural ibérico, les permitía que una amplia porción de la ciudadanía secundara sus demandas. Sin embargo, en la medida en que enmarcados de tipo violentos la equiparaban con otras asociaciones no pacíficas podían restarle apoyo. 
Queda abierta la vía de futuras investigaciones que ahonden en los estudios de audiencias que puedan determinar en qué medida son efectivos la instalación de determinados marcos y, por el contrario, cuales desalientan la movilización y atribuyen una imagen negativa descalificadora.

\section{Bibliografía}

Agencia Estatal Boletín Oficial del Estado (1978). Constitución Española. Recuperado 25 de mayo de 2015, desde: http://www.tribunalconstitucional.es/es/constitucion/Documents/ ConstitucionCASTELLANO.pdf.

Alemany, Adrià y Colau, Ada. (2012). Vidas hipotecadas. Romanyà Valls: Angle Editorial.

ASALE (Asociación de Academias de la Lengua Española) (2010). Escrache. En Diccionario de americanismos. Recuperado de: http://lema.rae.es/damer/?key=escrache. Última consulta: 25 de julio de 2018.

Carratalá Simón, Adolfo (2012). El discurso mediático conservador ante el debate sobre Educación para la Ciudadanía en España (2004-2008). Mediación social y comparación histórica con la prensa católica de la II República. Tesis doctoral. Valencia: Universitat de València.

Castells, Manuel. (2009). Comunicación y Poder. Trad. Hernández, María. Madrid: Alianza Editorial.

Cleaver, H. (1998). The Zapatistas and the international circulation of struggle. Lessons suggested and problems raised. Recuperado el 25 de julio de 2018 de https://la.utexas.edu/users/hcleaver/lessons.html.

Duman, Steve y Locher, Miriam (2008). "So let's talk. Let's chat. Let's start a dialogue: An analysis of the conversation metaphor employed in Clinton's and Obama's YouTube campaign clips". Multilingua, 27 (3) (pp. 193-230).

Gamson, William (1992). Talking Politics. United States of America: Cambridge University Press.

Hanna, Alexander (2013). "Computer-aided content analysis of digitally enabled movements". Mobilization: An International Quarterly, 18 (4) (pp. 367-388).

Kahn, Richard. y Kellner, Douglas. (2004). "New Media and Internet Activism: From the 'Battle of Seattle’ to Blogging”. New Media Society, vol. 6, pp. 87-95. Londres: Sage.

Montero Sánchez, María Dolores. (2001). "Mundialización y construcción de la opinión pública”. Anàlisi, núm. 26, pp. 103-119. Bellaterra: Universitat Autònoma de Barcelona, Servei de Publicacions.

Naciones Unidas (1948). Declaración Universal de los derechos humanos. Recuperado: 25 de julio de 2018, desde: http://www.un.org/es/documents/udhr/index print.shtml.

Offe, Claus (1996). Los nuevos movimientos sociales cuestionan los límites de la politica institucional. Partidos Políticos y nuevos movimientos sociales. Madrid: Editorial Sistema, p. 163-239.

Pérez Rioja, Beatriz. (2014). "El streamer, entre el periodismo ciudadano y ciberactivismo". Dentro de Eunate Serrano, Antonio Calleja-López, Arnau Monterde y Javier Toret (ed.). 
15MP2P. Una mirada transdisciplinar del 15M (pp. 64-75). Recuperado de: http://www.scribd.com/ doc/224680674/15MP2P-Una-mirada-transdisciplinar- del-15M. Última consulta: 16 de abril de 2015.

RAE (Real Academia Española) (2014). Escrachar. En Diccionario de la lengua española. Recuperado de: http://lema.rae.es/drae/?val=escrachar. Última consulta: 25 de julio de 2018.

Rivas, Antonio (1988). "El Análisis de marcos: una metodología para el estudio de los movimientos sociales”. En: IBARRA, Pedro y TEJERINA, Benjamín (Eds.) Los movimientos sociales. Transformaciones políticas y cambio cultural (pp. 181-215). Madrid: Editorial Trotta.

Rucht, Dieter (2004). "The quadruple 'A': media strategies of protest movements 25 since the 1960s”. Dentro de Wim van de Donk, Brian D.Loader, Paul G.Nixon y Dieter Rucht (Ed.). Cyberprotest: New media, citizens and social movements (pp. 25-48). Londres: Routledge.

Russell, Adrienne (2005). "Myth and the Zapatista movement: exploring a network identity". New Media Society, vol. 7, pp. 559-577. Londres: Sage.

Sala, Eduard (2018). "Análisis geográfico de la crisis hipotecaria: la distribución desigual a diferentes escalas". Biblio3W Revista Bibliográfica de Geografía y Ciencias Sociales, vol. 13, no. 1.256. Barcelona: Universidad de Barcelona.

Tarrow, Sidney (2004). Elpoder en movimiento: los movimientos sociales, la acción colectiva y la politica. Trad: Francisco Muñoz de Bustillo. Título original: Power in movement. Madrid: Alianza.

Vila Alabao, Nuria (2014). "Videoactivismo 2.0: revueltas, producción audiovisual en torno al 15M y cultura libre". Dentro de Eunate Serrano, Antonio Calleja-López, Arnau Monterde y Javier Toret (ed.). 15MP2P. Una mirada transdisciplinar del 15M (pp. 54-63).

YouTube (2015). Statistics. Recuperado: 28 de mayo de 2015, desde: http://www.youtube.com/yt/ press/statistics.html. 
MHCJ no 10 (1) | Año 2019 - Artículo no 1 (136) - Páginas 19 a 37 - mhjournal.org

\section{(c) (i) (2)}

Licencia Creative Commons

Miguel Hernández Communication Journal

mhjournal.org

\section{Cómo citar este texto:}

Ezequiel Ramon Pinat (2019): La batalla de los escraches de la PAH llevada a la pantalla: YouTube vs. RTVE, en Miguel Hernández Communication Journal, n¹0 (1), pp. 19 a 37. Universidad Miguel Hernández, UMH (Elche-Alicante). DOI: http://dx.doi.org/10.21134/mhcj.v10i0.274 